\title{
Simultaneous in-process control of weld pool geometry and heat affected zone based on thermal- optic imaging for welding of steel materials by concentrated energy fluxes
}

\author{
by G. Brüggemann ${ }^{1}$, J. Demus ${ }^{2}$ and Th. Benziger ${ }^{1}$ \\ ${ }^{1}$ Otto-von-Guericke-University Magdeburg, Institute for materials technology and materials testing, $D-$ \\ 39106 Magdeburg, Germany; ${ }^{2}$ Schweißtechnische Lehr- und Versuchsanstalt Halle GmbH, D-06118 \\ Halle/Saale, Germany

\begin{abstract}
Robot welding using high power energy flow processes is widely used in the fabrication industry for increasing productivity and enhancing product quality. The application of infrared thermography to the adaptive control of different welding processes is discussed in this paper.

Because these processes are difficult to control and automate, the quality of the product can vary over a large range. Therefore temperature gradients need to be controlled directly on-line with a high accuracy. This requires twodimensional temperature monitoring. A thermo-optic camera system can be used in order to investigate the cooling process in the weld seam area as well as in the heat affected zone. It was found that reasonable correlations exist between thermo-optical machine vision and weld seam quality, as far as weld pool geometry and thermal cycle interrogation is concerned.
\end{abstract}

\section{Introduction}

It is well accepted that the automation of most processes brings about a threefold increase in productivity. Specifically, when automating welding processes, it is recognised that there may still be some risk of defects and a more realistic estimate would be less than expected. The aim of the present paper is to demonstrate the feasibility of applying thermo-optic imagers to analyse data and thus provide high performance monitoring of complex welding processes.

Thermography allows to monitor in a remote way the actual surface temperature and the stationary two-dimensional temperature field $[1,2,3]$. Thereby one can observe the temperature gradient from the weld, through the heat affected zone (HAZ), to the base material.

Therefore thermography provides more information about the process than the visual observation by the operator. Qualitative and quantitative informations concerning the temperature and the movement of the weld pool, as well as the metallurgical reactions occuring in the weld pool, can be acquired $[4,5]$. These informations can be used as a criterion for the correction of the welding parameter, if necessary $[6,7]$.

\section{Infrared thermography in materials joining applications}

\subsection{Experimental configuration using CCD- and endicon-cameras}

The scene of fusion welding processes is characterised by great illumination differences. While the maximum intensity at GMA (gas metal arc) welding is in the ultraviolet and blue range of the spectra $(200<\lambda[\mathrm{nm}]<400)$, the welded piece emits mostly red and infrared light $(\lambda[\mathrm{nm}]$ $>600$ ) because its temperature is above $500^{\circ} \mathrm{C}$. At laser welding the temperature field is additionally shielded by the plasma $(400<\lambda[\mathrm{nm}]<800)$. The analysis of temperature fields of weld seams requires the application of spectral filters. During the GMA welding experiments, edge filters were applied to enable the monitoring of the melt pool by fading out the arc.

During the laser welding experiments, interference filters were applied because the laser plasma is transparent at some wavelengths. 


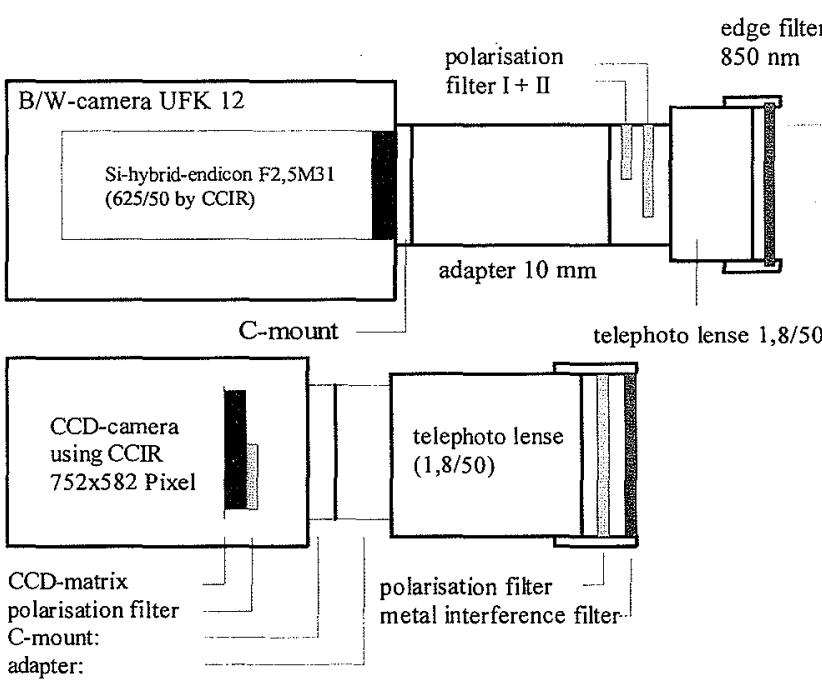

Fig. 1: Experimental configurations; Si-hybrid-endicon (top) and Si-CCDdetector (bottom) with corresponding optic and filter setup
For image recording two configurations of cameras and filters were applied. They are based on a silicon hybrid endicon and a CCD camera respectively.

Figure 1 shows the sensor equipment. For the analysis of the temperature fields, it is necessary to show the whole temperature range between $500^{\circ} \mathrm{C}$ and 1500 ${ }^{\circ} \mathrm{C}$ in only one image. This range is greater than what can be covered by the camera. In the camera objective an intermediate image plane is generated. In this plane the different regions of the image can be darkened. These filters can be varied in any way.

With a second lens the image is projected on the detector. In the image, one can see three areas of different sensitivity which can be varied in any way.

\subsection{Grey-scale-value-temperature calibration by comparison of the radiation fluxes}

The calibration of the sensor system was done using a specimen having the properties of a blackbody source. The experimental setup is shown in figure 2. For the heating of the specimen, a ceramic tube furnace was used. The specimen was positioned inside the tube. The

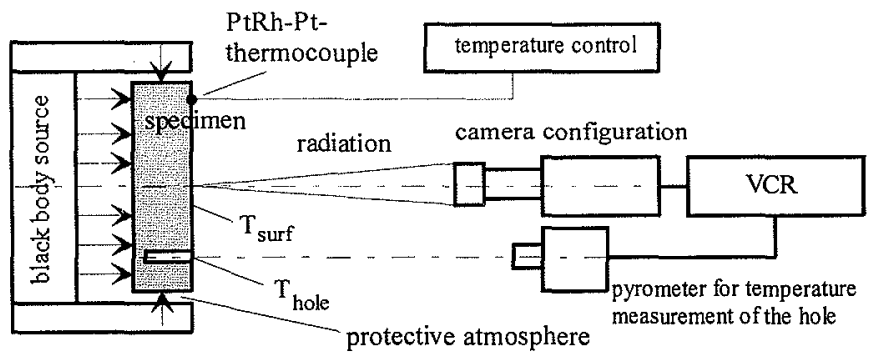

Fig. 2: temperature calibration by comparison of the radiation fluxes temperature was measured, in contact with the surface, using a PtRh-Ptthermocouple as well as contactless, with a pyrometer.

The number of greyscale values in the thermogram after the digitalization is limited to 256. This is caused by the characteristics of the digitizer. Also the dark current of the camera has to be considered. Hence a difference of grey scale values of $G-G_{0}=39$ has to be taken in account. By the online comparison between the virtual (measured by pyrometer) and the real temperature (measured by thermocouple), the emissivity of the steel under investigation can be determined.

It has been assumed that the emissivity in the interval $(500<\lambda[\mathrm{nm}]<1500)$ for a certain temperature is constant. An emissivity value of $\varepsilon=0,8$ showed the best results compared with experiments known from literature. So, this value was used for the calibration as is shown in figure 3 for $\times 2$ CrNiMoN 2253 . This curve was fitted with a polynom of $4^{\text {th }}$ order (1). 


$$
\begin{aligned}
& \mathrm{G}-\mathrm{G}_{0}=\mathrm{a} \cdot \mathrm{T}^{4}+\mathrm{b} \cdot \mathrm{T}^{3}+\mathrm{c} \cdot \mathrm{T}^{2}+\mathrm{d} \cdot \mathrm{T}+\mathrm{e} \\
& \mathrm{a}=6,79 \cdot 10^{-11} \mathrm{~b}=5,21 \cdot 10^{-7} \mathrm{c}=-1,3 \cdot 10^{-3} \mathrm{~d}=9,7 \cdot 10^{-1} \mathrm{e}=-226,79
\end{aligned}
$$

Because of the validity of WIEN's law, the curve can be approximated by an exponential function (2).

$$
\mathrm{G}-\mathrm{G}_{0}=\mathrm{a} \cdot \mathrm{e}^{-\frac{\overline{\mathrm{b}}}{\mathrm{T}}} \quad\left[\overline{\mathrm{b}}=10,81 \cdot 10^{4}, \mathrm{a}=4,2 \cdot 10^{7}\right]
$$

Applying this function one can

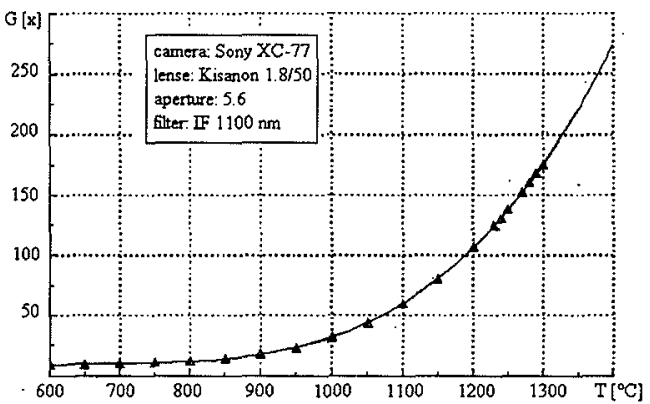

Fig. 3: calibration curve $G(x)=f(T)$ approximate the correlation between $b$ and the term $\frac{c_{2}}{\lambda}$ of WIENs law. Resulting from this a mean value $\bar{b}$ for all adjustments of filters and apertures was determined. Using this value the coefficient a was obtained more precisely for every adjustment. As a consequence of this improved determination of the quantity $a$, one can state that $b$ is constant for the respective values of $\varepsilon$. Only a has to be adapted. This is advantageous for the camera adjustment.

\section{Application in electric metal active arc $\left(\mathrm{CO}_{2}\right)$ welding of structural steels}

A series of tests was carried out using GMA welding. Test pieces used were St 38 mild steel plates having dimensions $200 \mathrm{~mm}$ in length, $100 \mathrm{~mm}$ in width and 5 and $10 \mathrm{~mm}$ in thickness. Beads on plate weids were laid using various process parameters such as arc current, welding voltage and welding speed. An automatic wire feeding unit was employed to provide variable wire feed rates, according to the arc current levels used.

\subsection{Proof of materials defects and inhomogeneities}

With remote monitoring of temperature distributions, defects and inhomogeneities near the surface of the sample can be visualised. Figure 4 (see color image) shows the temperature field of a weld in which a local build-up of heat is to be seen. The structure micrography shows a lamination which is the reason for this build-up of heat. Due to the lower heat conduction of the gap the temperature rises at those surface which faces the heat flow.

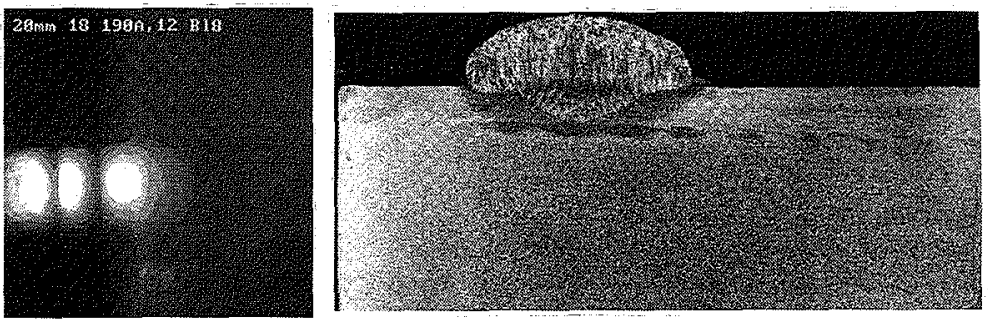

Fig. 4: Temperature field (4 bit grey scale) at $\mathrm{GMA}\left(\mathrm{CO}_{2}\right)$-welding and the corresponding macro structure (welding parameter: $I=190 \mathrm{~A}, U=25.5 \mathrm{~V}, \mathrm{~V}_{\mathrm{g}}=12 \mathrm{~cm} / \mathrm{min}, \mathrm{E}_{\mathrm{s}}=24,23 \mathrm{~kJ}$ ) 


\subsection{Estimation of the $t_{850^{\circ} \mathrm{C}-500^{\circ} \mathrm{C}}$ cooling time - prediction of mechanical properties}

The prediction of mechanical properties of a weld requires knowledge about the thermal

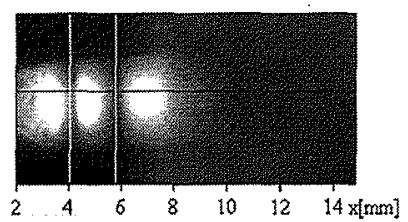

\begin{tabular}{|c|}
\hline weiding parameters: \\
\hline $\begin{array}{l}\text { laser: } \mathrm{CO}_{2}, 1500 \mathrm{~W} \\
\text { speed: } 0,75 \mathrm{~m} / \mathrm{min} \\
\text { St } 52-3 \mathrm{~N} \text {, th: } 3 \mathrm{~mm}\end{array}$ \\
\hline
\end{tabular}
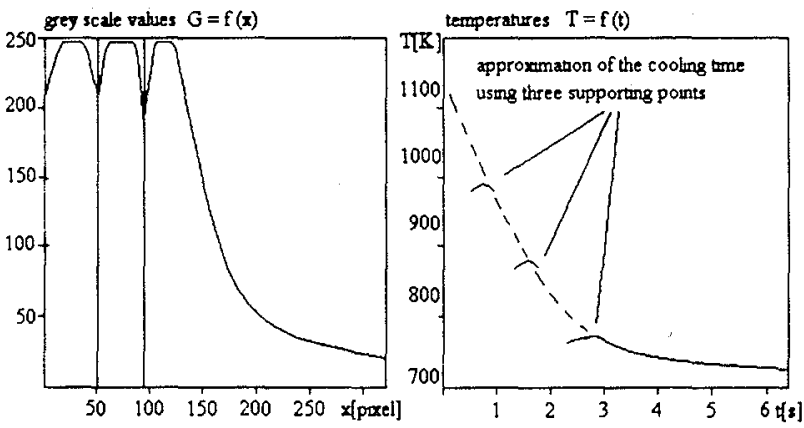

Fig. 5: Estimation of the cooling time $t_{8 / 5}$ using the correlation between the grey scale values and the corresponding temperatures

cycle and the transformation and excretion processes. From the literature some investigations are known which are based on the analytical or experimental determination of the cooling time between $850{ }^{\circ} \mathrm{C}$ and $500^{\circ} \mathrm{C}$. In this paper mainly the results of SEYFFARTH's work shall be used $[8,9]$. These results are referred to the socalled welding-timetemperature-conversion diagrams and to the regression equations for the prediction of mechanical properties of mild and carbon steels. The condition for the measurement of the cooling time $t_{e / 5}$ is a quasistationary temperature field. For the determination of the cooling time a greyscale line is placed in the temperature field acquired during the experiment. The following considerations have to be performed for the calculation of mechanical properties from the cooling time $t_{B / 5}$ determined using the grey-scale value lines.

The grey-scale values $G$ ( $y$-axis) are converted to temperature values using the parameters $a$ and $b$ (from the regression equations for the calibration functions of the camera) corresponding to the adjustment of aperture and filter. From eq. 2 it follows:

$$
T=\frac{-b}{\ln \left(G-G_{0}\right)-\ln a}[K]
$$

In figure 5 the function $G-G_{0}=f(x)$ as well as the function $T=f(t)$ are shown. It is, however, only possible to find approximations. Discontinuities between the temperature ranges are the reason for this fact. By calcuting the time difference one can obtain the value for the cooling time tas between $850^{\circ} \mathrm{C}$ and $500^{\circ} \mathrm{C}$.

If the cooling time and the chemical composition of the material are known, it is possible to predict expectations of the properties Vickers hardness, upper yield stress, tensile strength, breaking elongation and reduction of area after fracture.

\section{Application in beam welding of stainless steels}

\subsection{Laser and electron beam welding}

The thermal state of the material in the interaction zone is one of the main integrated parameters describing the evolution of physico-chemical processes and structural phase transformations in the surface layer of the material. From this point of view, the information about the dynamics of the surface temperature distribution of materials during irradiation are of major practical interest. Appreciable difficulties are encountered in the experimental determination of the surface temperature because of the specific measurement conditions: the 


\section{http://dx.doi.org/10.21611/qirt.1996.051}

small size of irradiation zone $(1-5 \mathrm{~mm})$, the wide range $(300-6000 \mathrm{~K})$ of temperature variation and the high rates. Under these conditions, the thermography is the most suitable.
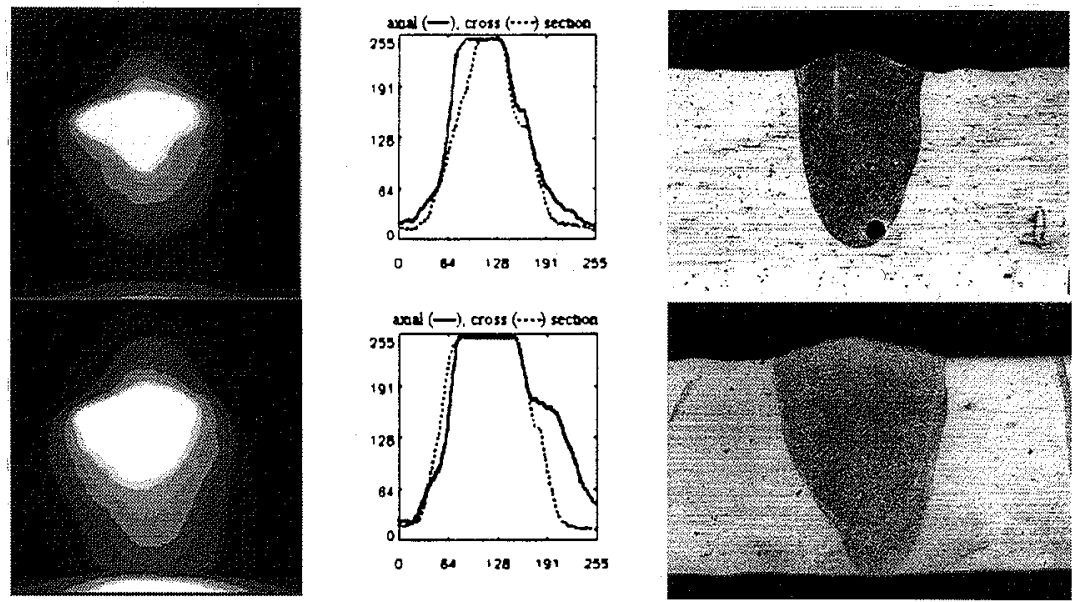

Fig. 6: temperature fields ( 4 bit grey scale) and gradients at laser welding of austenitic steels

Especially during the welding of austenitic steels, which are susceptible to hot cracking, it is necessary to control the heat flow. Figure 6 shows the temperature fields and temperature gradients during the welding of $X 1 \mathrm{NiCrMoCuN25205}$. The linescans are oriented in horizontal and vertical direction referring to the feed direction. If the cooling time is long enough, the susceptibility for solidification cracks is reduced. During the tests, the welding parameters remained constant, except the power $\left(P_{L}=1,0 \rightarrow 1,5 \mathrm{~kW}\right)\left(v_{r}=1 \mathrm{~m} / \mathrm{min}\right.$, th. $\left.=3 \mathrm{~mm}, q_{A r}=301 / \mathrm{min}\right)$.

\subsection{Plasma beam welding of austenitic-ferritic steels}
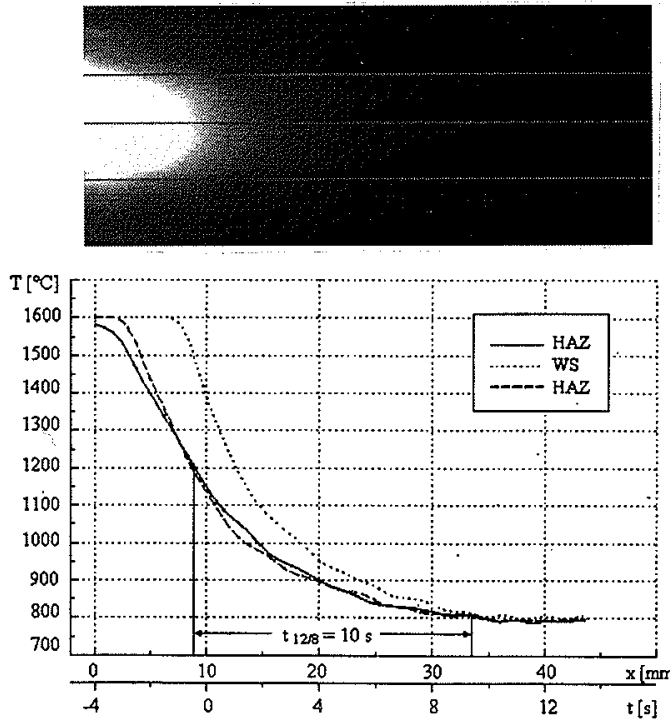

Fig. 7: Time and position dependent temperature gradients at plasma beam welding of duplex steel (th. $3 \mathrm{~mm}$ )
High alloyed stainless steels are resistant to corrosion and have a good deformation behaviour because of their chemical composition.

The aim is to obtain a correlation between the thermal cycle and the corrosion behaviour in the weld seam and in the HAZ of the duplex steel X2CrNiMoN22 53 , weided using a plasma beam. The temperature field around and immediately behind the weld pool can be observed. On this basis it is possible to determine the characteristic cooling times, e. g. the cooling time between 1200 and $800^{\circ} \mathrm{C}$, which is of special importance for duplex steels.

The acquired images were treated by image processing. Linescans in feed direction, as well as perpendicular to this direction. were extracted from the images. Figure 7 (see color table of the proceedings) shows, as an example, 
the time and position dependent temperature gradients for quasi stationary temperature fields. Depending on the time $t_{128}$ the portions of ferrite and austenite can be calculated. A cooling time $t_{i 28}$ of 10 seconds was found to be advantageous for the balance of both ferrite and austenite.

Investigations concerning the corrosion resistance revealed a clear reduction of the pitting corrosion temperature. Subsequent treatment of the surface with corrosive fluid showed an entanced resistance.

\section{Summary}

The application of infrared thermography for the monitoring of the conditions during the weiding of various steels is demonstrated by some selected results. The problems concerning the calibration of the acquisition equipment are discussed. A way to simplify the adjustment of the camera is shown. The application during GMA welding, laser beam and plasma beam welding reveals the special feasibilities of this technique. On the one hand it is possible to determine certain mechanical properties of the weld and the HAZ. On the other hand some defects near the surface can be visualised during their formation. The temperature cycle during welding can be monitored and shows to be important for different properties of the steels under investigation.

\section{Acknowledgements}

The authors are grateful to the staff of the Schweißtechnische Lehr- und Versuchsanstalt Halle/Saale $\mathrm{GmbH}$ for the experimental assistance and helpful discussion. This paper summarizes essential results of experiments in the frame of various research projects supported by the government of Saxony-Anhalt.

\section{REFERENCES}

[1] MALDAGUE (X.). - Nondestructive evaluation of materials by infrared thermography. London, Springer-Verlag, 1993.

[2] NAGARAJAN (S.). - Infrared techniques for real-time weld quality control. Maldague, $X$. (ed.): Infrared methodology and technology, Gordon \& Breach Sc. Pub., 1992, pp. 367-396

[3] KIM (1.); SIORES (E.); BASU (A.). - Infrared thermography for monitoring the robotic welding process. in: Non-destructive testing - Australia Vol. 32, No. 6. 11/12(1995), pp. 162-164

[4] MEYENDORF (N.); EHRLICH (S.); NITZSCHE (R.). - Thermographische Uberwachung von Schweißprozessen. Bild und Ton, Leipzig, 3/4(1992)45, pp. 55-59 [in German]

[5] LUCAS (W.). - Controle automatique de la penetration en soudage TIG. Soudage et techniques connexes, Paris, 9/10(1991)45, pp. 17-20 [in French]

[6] IGNATIEV (M.); ERMOLAEV (A.); TITOV (I.); SMUROV (I.). - High speed pyrometer system for laser welding, cutting, heat treatment and alloying processes temperature control. Mordike (B.) ed.; Laser treatment of materials, Proc. ECLAT'92, Göttingen, 1992, pp. 15-20

[7] BRÜGGEMANN (G.); HEINDÖRFER (F.). - Analyse thermogaphischer Bilddaten zur on-line Prozeßüberwachung beim Laserstrah/schweißen. Schweißen und Schneiden, DVS-Verlag Düsseldorf, 46(1994)12, pp. 622-626 [in German]

[8] SEYFFARTH (P.). - Aspects of the weldability of mild steels. Proc. $5^{\text {th }}$ ECLAT'94, Bremen. 1994. DVS-Verlag, Düsseldorf, Vol. 163, pp. 83-92

[9] KASSATKIN (O.).; SEYFFARTH (P.). - Interpolation models for evaluating the HAZ-phase composition in low-alloyed steel arc welding. IIW-Doc. XII-900-85 